\title{
Diagnostic Value of Screening Questions for Vestibular Dysfunction in HIV Disease: A Pilot Study
}

\author{
Peter L Nguy, MD ${ }^{1}$ (D), Deanna Ware, $\mathrm{MPH}^{2}$, Cameron Kelly ${ }^{2}$ (D) Michael Plankey, $\mathrm{PhD}^{2}$ (D) \\ ${ }^{1}$ Georgetown University School of Medicine, ${ }^{2}$ Department of Medicine, Georgetown University Medical Center \\ Keywords: vestibular function testing, screening survey, hiv, multicenter aids cohort study, women's interagency hiv study \\ https://doi.org/10.52504/001c.21372
}

\section{Georgetown Medical Review}

Vol. 5, Issue 1, 2021

\begin{abstract}
Introduction: A number of vestibular function tests have been used to evaluate vestibular symptoms among people living with HIV (PLWH). However, these tests are inconsistent due to poor sensitivity and specificity. This study attempts to identify sensitive and specific vestibular symptoms that may be useful in selecting appropriate HIV-positive adults for clinical vestibular function tests. Methods: Participants were enrolled from the Baltimore-Washington, DC, site of the Multicenter AIDS Cohort Study and the Washington, DC, site of the Women's Interagency HIV Study. A total of 246 participants were evaluated using the Dix-Hallpike (DH) maneuver and the eyes closed, standing on foam (ECF) position in the Romberg test, and completed the Adult Balance and Dizziness Supplemental questionnaire of the 2008 National Health Interview Survey. The sensitivity and specificity were calculated using self-reported vestibular dysfunction from the questionnaire data compared with vestibular dysfunction determined by clinical testing.

Results: Sixty participants $(24.4 \%)$ reported vestibular dysfunction. The prevalence of abnormal tests was $40.8 \%$ for DH-any nystagmus, $1.5 \%$ for DH-classical nystagmus, $40.3 \%$ for DH-nonclassical nystagmus, $38.3 \%$ for gazeevoked nystagmus, and $15.7 \%$ for Romberg ECF. Sensitivity of self-reported vestibular symptoms for all vestibular function tests reported ranged from $23.1 \%$ to $50.0 \%$. These symptoms were moderately specific and ranged from $73.3 \%$ to $77.9 \%$.

Conclusions: Despite adequate specificity, the low sensitivity of self-reported symptoms of vestibular dysfunction were not useful to rule out a vestibular disorder in this sample of middle-aged PLWH. Therefore, clinical testing is needed to confirm the diagnosis of a vestibular disorder in the management of HIV disease.
\end{abstract}

\section{Introduction}

Vestibular symptoms are characterized as vertigo, dizziness, and disequilibrium, with the most common cause being benign paroxysmal positional vertigo (BPPV), which is an inner-ear disorder creating a spinning sensation of the head. ${ }^{1}$ The effects of HIV on the vestibular system are well documented. $^{2-11}$ Castello et $\mathrm{al}^{12}$ found a $52 \%$ and $82 \%$ prevalence of corrective saccades and qualitative nystagmus abnormalities, respectively, among asymptomatic people living with HIV (PLWH), implying the involvement of the supratentorial areas, pons-cerebellar pathways, and the pretectal and paramedian pontine regions. Hausler et $\mathrm{al}^{13}$ reported an increase in abnormal central vestibular functioning in each stage of HIV infection, with $22 \%$ of patients with asymptomatic stage II disease presenting with abnormal vestibular functioning, 50\% of patients with stage III disease, and $57 \%$ of patients with stage IV disease. Further, Heinze et $\mathrm{al}^{6}$ reported that PLWH are 16.61 times more likely to develop vestibular involvement than HIV-negative 
individuals. Given the demonstrated prevalence of vestibular involvement in PLWH, it is important for health care providers to have accurate vestibular screening tools to demonstrate whether further vestibular function clinical testing is warranted. A number of vestibular function tests (VFTs) have been used in the evaluation of patients, including electronystagmography with bithermic caloric testing,, $12-16$ Romberg tests, 17 and more recently, cervical vestibular evoked myogenic potentials. ${ }^{6}$

A thorough patient history and physical examination are necessary in obtaining a correct diagnosis in patients with vestibular disorders. Hoffman et al ${ }^{18}$ noted in their review of 66 articles evaluating diagnostic testing of vestibular pathology that patient history led to an accurate diagnosis in $75 \%$ of patients with vestibular dysfunction. Other studies have corroborated the diagnostic utility of vestibular symptoms. ${ }^{19-23}$

Before subjecting the patient to a battery of clinical testing, it would be useful to identify certain screening questions that are more indicative of vestibular impairment. Previous studies have demonstrated the utility of screening questions in diagnosis. ${ }^{20-23}$ However, relatively few have correlated these with results from VFTs. Our study aims to identify sensitive and specific vestibular symptoms that may be useful in selecting appropriate candidates in the HIVpositive patient population for follow-up clinical testing.

\section{Methods}

\section{Ethics Statement}

The institutional review boards for Johns Hopkins University, Georgetown University, and Whitman-Walker Health approved this study. All participants signed informed consent prior to enrollment.

\section{Study Sample}

Participants were enrolled from the Baltimore-Washington, DC, site of the Multicenter AIDS Cohort Study (MACS) and the Washington, DC, site of the Women's Interagency HIV Study (WIHS). Both the MACS and WIHS are ongoing cohort studies of HIV infection in men and women, respectively.

This study is an extension of a 2012 study conducted by Cohen et $\mathrm{al}^{17}$ investigating vestibular function and balance in PLWH. The goal of this current study was to determine the sensitivity and specificity of self-reported symptoms of vestibular dysfunction compared with dysfunction determined by clinical testing, including the Dix-Hallpike (DH) maneuver and Romberg tests among the HIV-positive men and women only. Specifics of the testing paradigm and clinical evaluation were published elsewhere. ${ }^{17}$ Participants also completed the Adult Balance and Dizziness Supplemental questionnaire to the 2008 National Health Interview Survey. 24 
Table 1. Responses for Symptoms of Dizziness and Balance Problems Question ${ }^{\mathrm{a}}$

\begin{tabular}{|c|l|}
\hline Response & $\begin{array}{l}\text { Question 1: This next question is about symptoms of dizziness or balance problems. Please tell me if you have had any } \\
\text { of these in the past 12 months. } \\
\text { Please answer YES or NO to each. }\end{array}$ \\
\hline a & A spinning or vertigo sensation \\
\hline b & A floating, spacey, or tilting sensation \\
\hline c & Feeling lightheaded, without a sense of motion \\
\hline d & Feeling as if you are going to pass out or faint \\
\hline e & Blurring of vision when you move your head \\
\hline f & Feeling off-balance or unsteady \\
\hline
\end{tabular}

a This 6-part question was asked to study participants in order to assess self-reported vestibular disfunction. Participants answered either "yes" or "no" to each item, a through $\mathrm{f}$.

From March 2008 to September 2010, 545 potential participants were screened for eligibility for the study. Two HIV-positive men declined to participate in the process. Exclusions for enrollment into the 2012 study included spinal injury; radiation to the neck and spine; known vestibular impairment; and use of narcotics, antihistamines, or sedatives within 48 hours of testing. After exclusions, $247 \mathrm{HIV}$-positive people completed balance and vestibular testing. One limitation of this cohort sample is that it may not be representative of the HIV-positive population at large.

\section{Statistical Analysis}

Descriptive measures relevant to this study were age (5-year intervals), age (range), sex, and race/ethnicity. The Fisher exact test was performed on descriptive measures using GraphPad Prism version 8.4.3 for macOS.

One question eliciting symptoms of dizziness or balance problems in the last 12 months was identified from the Adult Balance and Dizziness Supplemental questionnaire to the 2008 National Health Interview Survey. Table 1 illustrates the question and its possible responses. Items $c$ and $d$ were deemed nonspecific responses and may arise from a myriad of other pathologies. ${ }^{1}$ Positive responses to those items were not considered to have reported true vestibular dysfunction. Positive responses to items $a, b, e$, and $f$ were defined as true vestibular dysfunction. Negative responses to all of these items were defined as not having vestibular dysfunction. One missing response to items a and $b$ were excluded from statistical analysis.

Data for each outcome variable were coded as either normal or abnormal using definitions previously defined in the 2012 study. ${ }^{17}$ The following outcome variables were included in the data analysis: DH-any nystagmus; $\mathrm{DH}$-nonclassical nystagmus; eyes closed, standing on foam (ECF) in the Romberg test, and gaze-evoked nystagmus. The number of $\mathrm{DH}$-classical nystagmus responses were too small for data analysis. Contingency tables were 
generated for each of the above outcome variables in relation to the participant's report of vestibular dysfunction. Sensitivity and specificity were then calculated using SAS version 9.4 (SAS Institute Inc).

\section{Results}

Table 2 shows the demographic characteristics of the participants. Overall, 246 participants answered the question regarding symptoms of dizziness or balance problems. Only 60 participants $(24.4 \%)$ reported vestibular dysfunction. Of those who reported vestibular dysfunction, the overall mean (SD) age was 49.4 (9.0) years. Black women reported more vestibular dysfunction than Black men $(73.0 \%$ vs $52.2 \% ; P=.16)$, but this is consistent with the relative proportions of Black women and men in the total sample population $(78.5 \%$ vs $53.6 \% ; P<.001)$. More women than men reporting vestibular dysfunction were diagnosed as having AIDS at least 1 year prior to vestibular function testing (45.9\% vs $30.4 \%)$, although the difference did not reach statistical significance $(P=.29)$. Fewer women had virologic suppression to undetectable levels $(43.2 \%$ vs $95.7 \% ; P<.001)$ or were currently taking highly active antiretroviral therapy $(73 \%$ vs $95.7 \% ; P<.001)$.

Table 3 reports the diagnostic values of self-reported symptoms in identifying an abnormal test result, as well as the prevalence of the abnormal test within the study sample. The number of missing values for Dix-Hallpike - any nystagmus, Dix-Hallpike - classical, Dix-Hallpike - nonclassical, Gaze-evoked nystagmus, and Romberg ECF were 18, 18, 18, 19, and 10, respectively. The prevalence of abnormal test results was $40.8 \%$ for $\mathrm{DH}$-any nystagmus, $1.5 \%$ for $\mathrm{DH}$-classical nystagmus, $40.3 \%$ for $\mathrm{DH}$-nonclassical nystagmus, $38.3 \%$ for gaze-evoked nystagmus, and $15.7 \%$ for Romberg ECF. Sensitivity of selfreported vestibular symptoms for all VFTs reported ranged from $23.1 \%$ to $50.0 \%$. However, these symptoms were moderately specific ranging from $73.3 \%$ to $77.9 \%$.

\section{Discussion}

Previously published work using symptoms as predictors of vestibular dysfunction have found different results regarding their value, citing higher sensitivity of symptoms in predicting benign paroxysmal positional vertigo $(\mathrm{BPPV}){ }^{21}$ Kentala and Rauch ${ }^{19}$ proposed a 3-parameter model (dizziness type, duration, and hearing loss) to assist in the triage of patients with dizziness. This instrument was only correct in classifying $60 \%$ of the participants but compared favorably with otoneurological expert systems. Oghalai et $\mathrm{al}^{21}$ indicated in their study of geriatric patients that the sensation of spinning without lightheadedness was $56 \%$ sensitive for BPPV. Halmagyi ${ }^{22}$ found in a review of diagnosis and management of BPPV that certain activities eliciting vertigo are clear indicators of $\mathrm{BPPV}$, such as turning in bed at night or looking under the car. Zhao et $\mathrm{al}^{23}$ corroborated the utility of patient symptoms in facilitating diagnosis, reporting that certain variables were significant predictors of the disease. 
Table 2. Descriptive Characteristics of the Sample by Sex

\begin{tabular}{|c|c|c|c|c|c|c|}
\hline & \multicolumn{3}{|c|}{ Reported vestibular dysfunction } & \multicolumn{3}{|c|}{ Did not report vestibular dysfunction } \\
\hline & Male & Female & All & Male & Female & All \\
\hline No. of patients & 23 & 37 & 60 & 102 & 84 & 186 \\
\hline Age, mean (SD), y & $\begin{array}{l}53.9 \\
(7.9)\end{array}$ & $\begin{array}{l}46.7 \\
(8.6)\end{array}$ & $\begin{array}{l}49.4 \\
(9.0)\end{array}$ & $\begin{array}{l}51.6 \\
(8.0)\end{array}$ & $\begin{array}{l}45.1 \\
(8.6)\end{array}$ & $\begin{array}{l}48.7 \\
(8.9)\end{array}$ \\
\hline \multicolumn{7}{|l|}{ Race, No. (\%) } \\
\hline Not Black & $\begin{array}{c}11 \\
(47.8)\end{array}$ & $\begin{array}{c}10 \\
(27.0)\end{array}$ & $\begin{array}{c}21 \\
(35.0)\end{array}$ & $\begin{array}{c}47 \\
(45.6)\end{array}$ & $\begin{array}{c}16 \\
(19.0)\end{array}$ & $\begin{array}{c}63 \\
(33.7)\end{array}$ \\
\hline Black & $\begin{array}{c}12 \\
(52.2)\end{array}$ & $\begin{array}{c}27 \\
(73.0)\end{array}$ & $\begin{array}{c}39 \\
(65.0)\end{array}$ & $\begin{array}{c}55 \\
(53.9)\end{array}$ & $\begin{array}{c}68 \\
(81.0)\end{array}$ & $\begin{array}{c}123 \\
(66.1)\end{array}$ \\
\hline Ever AIDS, No. (\%) & $\begin{array}{c}7 \\
(30.4)\end{array}$ & $\begin{array}{c}17 \\
(45.9)\end{array}$ & $\begin{array}{c}24 \\
(40)\end{array}$ & $\begin{array}{c}15 \\
(14.6)\end{array}$ & $\begin{array}{c}27 \\
(32.1)\end{array}$ & $\begin{array}{c}42 \\
(22.5)\end{array}$ \\
\hline \multicolumn{7}{|l|}{ Previous therapy, No. (\%) } \\
\hline No therapy & $\begin{array}{c}1 \\
(4.3)\end{array}$ & $\begin{array}{c}8 \\
(21.6)\end{array}$ & $\begin{array}{c}9 \\
(15.0)\end{array}$ & $\begin{array}{c}16 \\
(15.5)\end{array}$ & $\begin{array}{c}25 \\
(29.8)\end{array}$ & $\begin{array}{c}41 \\
(21.9)\end{array}$ \\
\hline Ever monotherapy & 0 & 0 & 0 & 0 & 0 & 0 \\
\hline Ever combo therapy & 0 & $\begin{array}{c}2 \\
(5.4)\end{array}$ & $\begin{array}{c}2 \\
(3.3)\end{array}$ & $\begin{array}{c}4 \\
(3.9)\end{array}$ & $\begin{array}{c}1 \\
(1.2)\end{array}$ & $\begin{array}{c}5 \\
(2.7)\end{array}$ \\
\hline Ever HAART & $\begin{array}{c}22 \\
(95.7)\end{array}$ & $\begin{array}{c}27 \\
(73.0)\end{array}$ & $\begin{array}{c}49 \\
(81.7)\end{array}$ & $\begin{array}{c}82 \\
(80.4)\end{array}$ & $\begin{array}{c}58 \\
(69.1)\end{array}$ & $\begin{array}{c}140 \\
(75.3)\end{array}$ \\
\hline $\begin{array}{l}\text { Current HAART use, No. } \\
\text { (\%) }\end{array}$ & $\begin{array}{c}22 \\
(95.7)\end{array}$ & $\begin{array}{c}27 \\
(73.0)\end{array}$ & $\begin{array}{c}49 \\
(81.7)\end{array}$ & $\begin{array}{c}82 \\
(80.4)\end{array}$ & $\begin{array}{c}58 \\
(69.1)\end{array}$ & $\begin{array}{c}140 \\
(75.3)\end{array}$ \\
\hline \multicolumn{7}{|l|}{$\mathrm{CD} 4+$, mean $(\mathrm{SD})$} \\
\hline Nadir & $\begin{array}{l}225.50 \\
(151.4)\end{array}$ & $\begin{array}{l}248.84 \\
(226.2)\end{array}$ & $\begin{array}{l}239.82 \\
(199.8)\end{array}$ & $\begin{array}{l}296.80 \\
(175.6)\end{array}$ & $\begin{array}{l}262.83 \\
(161.7)\end{array}$ & $\begin{array}{l}281.45 \\
(169.9)\end{array}$ \\
\hline Current & $\begin{array}{l}545.52 \\
(352.9)\end{array}$ & $\begin{array}{l}536.68 \\
(312.9)\end{array}$ & $\begin{array}{l}540.07 \\
(325.9)\end{array}$ & $\begin{array}{l}574.00 \\
(260.1)\end{array}$ & $\begin{array}{l}546.60 \\
(283.8)\end{array}$ & $\begin{array}{l}561.61 \\
(270.7)\end{array}$ \\
\hline \multicolumn{7}{|l|}{ CD8+, mean (SD) } \\
\hline Peak & $\begin{array}{c}1370.22 \\
(714.2)\end{array}$ & $\begin{array}{l}1409.86 \\
(541.4)\end{array}$ & $\begin{array}{l}1394.67 \\
(607.8)\end{array}$ & $\begin{array}{l}1491.00 \\
(701.6)\end{array}$ & $\begin{array}{c}1354.94 \\
(703.6)\end{array}$ & $\begin{array}{c}1429.55 \\
(703.9)\end{array}$ \\
\hline Current & $\begin{array}{l}888.96 \\
(439.1)\end{array}$ & $\begin{array}{l}855.73 \\
(302.0)\end{array}$ & $\begin{array}{l}868.47 \\
(357.5)\end{array}$ & $\begin{array}{l}911.00 \\
(397.0)\end{array}$ & $\begin{array}{l}783.20 \\
(384.9)\end{array}$ & $\begin{array}{c}853.26 \\
(395.70)\end{array}$ \\
\hline $\begin{array}{l}\text { Undetectable viral load, } \\
\text { No. (\%) }\end{array}$ & $\begin{array}{c}22 \\
(95.7)\end{array}$ & $\begin{array}{c}16 \\
(43.2)\end{array}$ & $\begin{array}{c}38 \\
(63.3)\end{array}$ & $\begin{array}{c}76 \\
(74.5)\end{array}$ & $\begin{array}{c}44 \\
(52.4)\end{array}$ & $\begin{array}{c}120 \\
(64.5)\end{array}$ \\
\hline $\begin{array}{l}\text { Log viral load, median } \\
\text { (IQR) }\end{array}$ & $\begin{array}{c}1.602 \\
(1.60-1.60)\end{array}$ & $\begin{array}{c}2.017 \\
(1.68-3.52)\end{array}$ & $\begin{array}{c}1.681 \\
(1.60-2.83)\end{array}$ & $\begin{array}{c}1.080 \\
(1.60-1.77)\end{array}$ & $\begin{array}{c}1.903 \\
(1.68-3.21)\end{array}$ & $\begin{array}{c}1.681 \\
(1.60-2.77)\end{array}$ \\
\hline
\end{tabular}

Abbreviations: HAART, highly active antiretroviral therapy; IQR, interquartile range.

However, our study finds far less utility in these symptoms as a means of screening due to their low sensitivity. Comparing self-reported symptoms with the results from VFTs used in the original 2012 study by Cohen et al, ${ }^{17}$ our sensitivity was low, ranging from $23.1 \%$ to $50.0 \%$. This low range thus increases the chance of missing a patient who may be positive for vestibular dysfunction as defined by VFT. On the contrary, most of the self-reported symptoms had moderate specificity. As such, with moderate specificity, a negative response is adequately likely to correspond to a true lack of vestibular dysfunction. Given the questionable utility of these questions based on variable sensitivity and specificity, they are imperfect proxies for true vestibular dysfunction. In addition, determining whether self-reported symptoms can accurately predict a positive VFT result is limited by potential recall error. 
Table 3. Sensitivity, specificity, and prevalence of vestibular function for each test

\begin{tabular}{|c|c|c|c|c|}
\hline & $\begin{array}{l}\text { Sensitivity \% } \\
\text { (n-ratio) }\end{array}$ & $\begin{array}{l}\text { Specificity \% } \\
\text { (n-ratio) }\end{array}$ & $\begin{array}{l}\text { Prevalence } \\
\text { (n-ratio) }\end{array}$ & $\begin{array}{c}\text { Missing Test values } \\
\mathrm{n}\end{array}$ \\
\hline Dix-Hallpike, any nystagmus & $\begin{array}{l}23.7 \% \\
(22 / 93) \\
\end{array}$ & $\begin{array}{c}73.3 \% \\
(99 / 135) \\
\end{array}$ & $\begin{array}{c}40.8 \% \\
(93 / 228) \\
\end{array}$ & 18 \\
\hline Dix-Hallpike, classical & $\begin{array}{l}50.0 \% \\
(1 / 2)\end{array}$ & $\begin{array}{c}73.3 \% \\
(99 / 135)\end{array}$ & $\begin{array}{c}1.5 \% \\
(2 / 137)\end{array}$ & 18 \\
\hline Dix-Hallpike, nonclassical & $\begin{array}{l}23.1 \% \\
(21 / 91)\end{array}$ & $\begin{array}{c}73.3 \% \\
(99 / 169)\end{array}$ & $\begin{array}{c}40.3 \% \\
(91 / 226)\end{array}$ & 18 \\
\hline Gaze-evoked nystagmus & $\begin{array}{c}26.4 \% \\
(23 / 87) \\
\end{array}$ & $\begin{array}{c}75.0 \% \\
(105 / 140) \\
\end{array}$ & $\begin{array}{c}38.3 \% \\
(87 / 227) \\
\end{array}$ & 19 \\
\hline Romberg ECF & $\begin{array}{c}37.8 \% \\
(14 / 37)\end{array}$ & $\begin{array}{c}77.9 \% \\
(155 / 199)\end{array}$ & $\begin{array}{c}15.7 \% \\
(37 / 236)\end{array}$ & 10 \\
\hline
\end{tabular}

Abbreviation: ECF: eyes closed, standing on foam.

\section{Conclusions}

The moderate specificity of self-reported symptoms of vestibular dysfunction is potentially useful to rule out a vestibular disorder in this sample of middleaged PLWH. However, the low sensitivity indicates that self-reported symptoms could not accurately predict vestibular dysfunction. This pilot study will be expanded in the future to collect data from a larger sample size within the cohorts of HIV-positive men and women.

\section{Conflicts of interest}

These authors contributed equally to the work and report no conflicts of interest.

\section{Disclosure statement}

No financial disclosures were reported by the authors of this paper.

\section{Corresponding Author:}

Michael Plankey, PhD

Georgetown University Medical Center

3800 Reservoir Road, NW

Department of Medicine

PHC $5^{\text {th }}$ Floor

Washington, DC 20007

Phone: 202-784-2687

mwp23@georgetown.edu

\section{Acknowledgements}

The contents of this publication are solely the responsibility of the authors and do not represent the official views of the National Institutes of Health (NIH). The Multicenter AIDS Cohort Study (MACS)/Women's Interagency HIV Study (WIHS) Combined Cohort Study (MWCCS) include the following: 
principal investigators: Baltimore CRS (Todd Brown and Joseph Margolick), U01-HL146201; data analysis and coordination center (Gypsyamber D’Souza, Stephen Gange, and Elizabeth Golub); and Metropolitan Washington CRS (Seble Kassaye and Daniel Merenstein), U01-HL146205. The MWCCS is funded primarily by the National Heart, Lung, and Blood Institute, with additional co-funding from the Eunice Kennedy Shriver National Institute of Child Health \& Human Development, National Institute on Aging, National Institute of Dental and Craniofacial Research, National Institute of Allergy and Infectious Diseases, National Institute of Neurological Disorders and Stroke, National Institute of Mental Health, National Institute on Drug Abuse, National Institute of Nursing Research, National Cancer Institute, National Institute on Alcohol Abuse and Alcoholism, National Institute on Deafness and Other Communication Disorders, National Institute of Diabetes and Digestive and Kidney Diseases, National Institute on Minority Health and Health Disparities, and in coordination and alignment with the research priorities of the NIH, Office of AIDS Research. MWCCS data collection is also supported by grants UL1-TR000004 (UCSF CTSA), P30-AI-050409 (Atlanta CFAR), P30-AI-050410 (UNC CFAR), and P30-AI-027767 (UAB CFAR). The MWCCS website is http://www.mwccs.org. The study investigators thank the MACS men and WIHS women for participating in this pilot study. 


\section{REFERENCES}

1. Lang EE, McConn Walsh R. Vestibular function testing. Ir J Med Sci. 2010;179(2):173-178. doi:10.1007/s11845-010-0465-7

2. Gurney TA, Murr AH. Otolaryngologic manifestations of human immunodeficiency virus infection. Otolaryngol Clin North Am. 2003;36(4):607-624. doi:10.1016/s0030-6665(03)00031-8 3. Rinaldo A, Brandwein MS, Devaney KO, Ferlito A. AIDS-related otological lesions. Acta Otolaryngol. 2003;123(6):672-674. doi:10.1080/00016480310000629a

4. Chandrasekhar SS, Connelly PE, Brahmbhatt SS, Shah CS, Kloser PC, Baredes S. Otologic and audiologic evaluation of human immunodeficiency virus-infected patients. Amer J Otolaryngol. 2000;21(1):1-9. doi:10.1016/s0196-0709(00)80117-9

5. Heinze B, Swanepoel DW, Hofmeyr LM. Systematic review of vestibular disorders related to human immunodeficiency virus and acquired immunodeficiency syndrome.J Laryngol Otol. 2011;125(9):881-890. doi:10.1017/s0022215111001423

6. Heinze BM, Vinck BM, Hofmeyr LM, Swanepoel DW. Vestibular involvement in adults with HIV/AIDS. Auris Nasus Larynx. 2014;41(2):160-168. doi:10.1016/j.anl.2013.08.003

7. Chandrasekhar SS, Silverls V, Sekhar HK. Histopathologic and ultrastructural changes in the temporal bones of HIV-infected human adults. Am J Otol. 1992;13(3):207-214.

8. Pappas DGJ Jr, Roland JTJ Jr, Lim J, Lai A, Hillman DE. Ultrastructural findings in the vestibular end-organs of AIDS cases. Am J Otol. 1995;16(2):140-145.

9. Khoza K, Ross E. Auditory function in a group of adults infected with HIV/AIDS in Gauteng, South Africa. S Afr J Commun Disord. 2002;49(1):17-27. doi:10.4102/sajcd.v49i1.214

10. Marra CM, Wechkin HA, Longstreth WT Jr, Rees TS, Syapin CL, Gates GA. Hearing loss and antiretroviral therapy in patients infected with HIV-1. Arch Neurol. 1997;54(4):407-410.

doi:10.1001/archneur.1997.00550160049015

11. Alabi BS, Salami AK, Afolabi OA, et al. Otologic and audiologic evaluation among HIV patients in Ilorin, Nigeria. Nig QJ Hosp Med. 2013;23(1):29-32.

12. Castello E, Baroni N, Pallestrini E. Neurotological auditory brain stem response findings in human immunodeficiency virus-positive patients without neurologic manifestations. Ann Otol Rhinol Laryngol. 1998;107(12):1054-1060. doi:10.1177/000348949810701210

13. Hausler R, Vibert D, Koralnik IJ, Hirschel B. Neuro-otological manifestations in different stages of HIV infection. Acta Otolaryngol Suppl. 1991;48:515-521. doi:10.3109/ $\underline{00016489109131461}$

14. Teggi R, Giordano L, Pistorio V, Bussi M. Vestibular function in HIV: Preliminary report. Acta Otorholaryngol Ital. 2006;26(3):140-146.

15. Teggi R, Ceserani N, Luce FL, Lazzarin A, Bussi M. Otoneurological findings in human immunodeficiency virus positive patients.J Laryngol Otol. 2008;122(12):1289-1294. doi:10.1017/ $\underline{\mathrm{s} 0022215107001624}$

16. Mathews SS, Albert RR, Job A. Audio-vestibular function in human immunodeficiency virus infected patients in India. Indian J Sex Transm Dis AIDS. 2012;33(2):98-101. doi:10.4103/ $\underline{0253-7184.102115}$

17. Cohen HS, Cox C, Springer G, et al. Prevalence of abnormalities in vestibular function and balance among HIV-seropositive and HIV-seronegative women and men. Sluis-Cremer N, ed. PLoS ONE. 2012;7(5):e38419. doi:10.1371/journal.pone.0038419

18. Hoffman RM, Einstadter D, Kroenke K. Evaluating dizziness. Am J Med. 1999;107(5):468-478. doi:10.1016/s0002-9343(99)00260-0 
19. Kentala E, Rauch SD. A practical assessment algorithm for diagnosis of dizziness. Otolaryngol Head Neck Surg. 2003;128(1):54-59. doi:10.1067/mhn.2003.47

20. Noda K, Ikusaka M, Ohira Y, Takada T, Tsukamoto T. Predictors for benign paroxysmal positional vertigo with positive Dix-Hallpike test. Int J Gen Med.2011;4:809-814. doi:10.2147/ ijgm.s27536

21. Oghalai JS, Manolidis S, Barth JL, Stewart MG, Jenkins HA. Unrecognized benign paroxysmal positional vertigo in elderly patients. Otolaryngol Head Neck Surg. 2000;122(5):630-634. doi:10.1016/s0194-5998(00)70187-2

22. Halmagyi GM. Diagnosis and management of vertigo. Clin Med. 2005;5(2):159-165. doi:10.7861/clinmedicine.5-2-159

23. Zhao JG, Piccirillo JF, Spitznagel EL Jr, Kallogjeri D, Goebel JA. Predictive capability of historical data for diagnosis of dizziness. Otol Neurotol. 2011;32(2):284-290. doi:10.1097/ $\underline{\operatorname{mao} .0 \mathrm{~b} 013 \mathrm{e} 318204 \mathrm{aad} 3}$

24. Centers for Disease Control and Prevention. Adult Physical Activity Questions on the National Health Interview Survey, 2008 National Health Interview Survey-Adult Balance and Dizziness Supplement, 1975-2012. Accessed January 4, 2021. https:/www.cdc.gov/nchs/data/nhis/ physicalactivity/pa_questions.pdf 